\title{
Abstracts
}

\section{Pensions for South Africans}

Frances Lund. 1993. State social benefits in South Africa. International Social Security Review, 46, 1, 5-25.

Elisabeth Ardington and Frances Lund, I995. Pensions and development: social security as complementary to programmes of reconstruction and development. Development Southern Africa, 12, 4, $557-577$.

Does South Africa's social security system have a role to play in eliminating inequality and poverty in South Africa, a key aim underlying the country's reconstruction and development programme in the post-apartheid era? The transition to democratic government has made urgent the concern to overcome the poverty and inequality which have beset South Africa. Since the first democratic elections in April 1994, much energy has been invested in the planning and design of ambitious programmes of social and economic development for the country, the most notable being the Reconstruction and Development Programme (RDP).

In the first article, Lund provides an excellent introduction to the South African welfare system on the eve of the elections. She discusses major problems and inefficiencies in the state social pension system and draws attention to positive features which could be the basis for a better system in future. The author explains that the South African old age pension is a universal and non-contributory benefit. South Africa is cited as one of only two African countries whose pension systems are universal and non-contributory. The pension is payable to women and men on reaching the ages of 60 and 65 years of age respectively, although the government is currently trying to equalize the eligible age at 65 years. It is means-tested: there are exclusion levels of income and assets, and once in, a sliding scale is applied. However, Lund found that in many rural areas, the exclusion levels were so low that nearly all qualified; some former administrations virtually ceased to apply the means test. The old age pension is paid out of general revenue. For the nation as a whole, in 1990 old age pensions were 67 per cent of all social security spending. In 1991 it was estimated that I. I million of about 32 million people were old age pensioners. 
The pensions system in South Africa was first designed for the white population, with the British model in mind. Its scope and coverage were gradually extended to the whole population, though with unequal payments to other race groups. During the I980s and I 990 os it became politically inevitable that benefits would have to be equalised. Racial parity was achieved in September 1 993. Lund argues that parity raises the possibility of the scheme being a significant mechanism for poverty alleviation. For the African rural population, the old age pension is claimed by individuals, but it is largely consumed as a household asset in the three-generational families in which most rural pensioners live. Migrant remittances and pensions are the two most important sources of income for rural households. In 1993, the take-up rate for black women and men was 77 and 80 per cent respectively. At the time of writing, KwaZulu, one of the most densely populated and poorest regions in South Africa, was piloting a scheme to privatize the delivery of social pensions. A method of identification of pensioners by fingerprint has been designed to eliminate abuse of the system and to make sure that benefits reach elderly people. During apartheid pensions were administered by 17 separate welfare departments. Lund argues that it is very difficult to take seriously the notion of pensions being too expensive given the bureaucratic fragmentation. The dilemma, as Lund sees it, is that it is nearly impossible to gauge the weight of pensions' spending, now and in future, relative to other important and competing social budgetary items such as housing, education and health.

The second article by Ardington and Lund updates the social security debate. It critically examines the assumption that social security payments are antithetical to the objectives of development programmes. A secondary analysis of information on over 5,00o black households in the former KwaZulu is presented to enable policy makers better to understand how the old age pension system currently works. Drawing on this database, the article poses critical questions concerning the extent of pension coverage, whether pensions reach rural people and the poorest of the poor, and how much pensions contribute to household income. The results indicate that pensions were making a substantial difference to the levels of living in households in poverty, except for the very poorest. The poorest of the poor were in that position partly because of their restricted access to pension income. The fact that some 85 per cent of pensioners lived in three-generational households, and that poorer households had more members than others, further suggested that pensions benefited a far wider segment of the population than the 4.5 per cent who received them. 
The authors have in the past consistently argued that pensions are a significant source of income, with marked redistributive effects; that they are a reliable source of income, which leads to household security; that they are the basis of credit facilities in local markets, further contributing to food security; that they deliver cash into remote areas where no other institutions reach; that they are gender-sensitive towards women; and that they reach rural areas as few other services do. The results substantiate these claims. Aware that their observations are based on cross-sectional data, the authors are cautious about suggesting that they have provided conclusive evidence. However, they note that the dynamics of poverty in KwaZulu may be similar to those in other parts of the country. Results from a more recent country-wide study of poverty have confirmed some of their findings.

In their conclusion, Ardington and Lund return to the question of where the social security system fits in the overall programme of reconstruction and development. The size of the security budget causes concern, particularly considering urgent needs in the areas of education, housing and health. In the r 994 budget of R I 43 billion, social security and social services were allocated $\mathrm{R}_{13}$ billion while health received about $\mathrm{R}_{14}$ billion. Ardington and Lund hold the opinion that the recent increases in pensions to the black population (to achieve parity across the races) has had a far greater and more direct impact on poverty reduction than most of the other development efforts that have proceeded for decades. Their analysis has shown that pensions perform very well in distributing income to rural areas. The authors note that this is an unusual effect for pensions or any other social security system in developing countries.

More research is needed to gain a better understanding of who the poor are and of their needs. Meanwhile it is recommended that the social system should take its place alongside other social programmes of reconstruction and development so that transfers can continue to support those who cannot support themselves. Ardington and Lund argue that the social security system should be seen as not in competition with the broader programmes of reconstruction and development but as complementary. Pensions provide the underpinning of household and food security which the programmes of reconstruction and development seek to achieve. The designers of new programmes should take into account this parallel track which provides security to so many people.

In the face of the major institutional changes which the country is experiencing, it would be best to maintain these mechanisms of redistribution, as limited and inadequate as they may be. They lean in 
the correct direction and are in place. Over the longer term, if levels of inequality are reduced, it should be possible to reduce the emphasis on state-provided pensions.

Centre for Social and Development Studies,

University of Natal,

Dalbridge, 4014, Durban

\section{Medicine and Society}

Stephen Curran

There is a tendency for doctors to regard physical and mental illness in elderly people as an 'understandable part of growing old'. This often results in physical and mental disorders not being recognised and/or adequately treated. These abstracts illustrate some of the barriers, including negative attitudes and lack of knowledge, which exist and prevent elderly people from reaching their full potential.

Wilcock, G. 1995. Alzheimer's disease - a continuum of or contributed to by normal ageing? Alzheimer's Research, I(2), 6I-65.

The relationship between normal ageing and Alzheimer's disease has been debated for a considerable time and the topic remains controversial. Alzheimer's disease is well known to be predominantly a disease of late life and the prevalence of the condition increases with increasing age. Professor Wilcock reviews this area and asks the question, is Alzheimer's disease a continuum of or contributed to by normal ageing? He examines diverse areas including the ageing process and epidemiological, neuropathological and biochemical evidence. He concludes that, 'whether or not Alzheimer's disease is on a continuum, or an exaggeration of the normal ageing process existing as a continuum with the former, will to some extent depend upon the definition of normal ageing'. There is a strong body of evidence supporting both the continuum hypothesis and the 'exaggeration of normal' view of Alzheimer's disease. The crucial point made by the author is that 'the pitfall that must be avoided at all costs is one that has dogged medicine for the elderly for many years... (namely) the assumption that disability and dysfunction in old age are caused by anno domini and do not merit scientific endeavour'. Consequently when and if this debate is resolved there may be important implications for the way society as a whole views people with Alzheimer's disease and elderly people generally. 